\title{
Chitosan gel vaccine protects against tumour growth in an intracaecal mouse model of cancer by modulating systemic immune responses
}

\author{
Andrew J. Highton', Adam Girardin', Georgia M. Bell', Sarah M. Hook² and Roslyn A. Kemp ${ }^{1 *}$
}

\begin{abstract}
Background: Vaccination generating a robust memory population of $\mathrm{CD} 8^{+} \mathrm{T}$ cells may provide protection against cancer. However, immune therapies for cancer are influenced by the local tumour immune microenvironment. An infiltrate of T cells into tumours of people with colorectal cancer has proven to be a significant indicator of good prognosis.

Methods: We used an intracaecal mouse model of cancer to determine whether a protective immune response against a mucosal gut tumour could be generated using a systemic intervention. We investigated the generation of murine memory CD8 ${ }^{+} T$ cells using a sustained antigen release vaccine vehicle (chitosan gel; Gel + OVA) containing the model antigen ovalbumin, chitosan gel alone (Gel) or conventional dendritic cell vaccination (DC + OVA) using the same protein antigen.

Results: Following vaccination with Gel $+\mathrm{OVA}, \mathrm{CD}^{+} \mathrm{T}$ cell memory populations specific for ovalbumin protein were detected. Only vaccination with Gel + OVA gave decreased tumour burden compared to unvaccinated or DC + OVA-vaccinated mice in the intracaecal cancer challenge model.

Conclusion: These results indicate that subcutaneous vaccination with Gel + OVA generates a population of functional $\mathrm{CD}^{+}$memory T cells in lymphoid tissue able to protect against intracaecal tumour challenge.

Vaccination with chitosan gel may be valuable in anti-cancer treatment at both peripheral and mucosal sites.
\end{abstract}

Keywords: Colon cancer, IFN- $\gamma$, T cells, Vaccination, Tumour, Caecum

\section{Background}

Colorectal cancer $(\mathrm{CRC})$ is the fourth leading cause of cancer related death worldwide [1]. In most cases, the disease occurs sporadically but can also be preceded by inflammatory bowel disease or a familial genetic predisposition, for example, familial adenomatous polyposis (FAP) [2, 3]. As with other cancers, the immune system plays a large role in the control of disease. Work by Galon et al has shown that a large infiltrating population of $\mathrm{CD}^{+} \mathrm{T}$ cells predicts improved patient outcome [4]. More mixed results have been obtained regarding other

\footnotetext{
*Correspondence: roslyn.kemp@otago.ac.nz

'Department of Microbiology and Immunology, Otago School of Medical Sciences, University of Otago, PO Box 56, Dunedin 9054, New Zealand Full list of author information is available at the end of the article
}

immune cell populations in tumour tissue and their relation to patient outcome [5-8].

The gut is an immunosuppressive environment and control of local disease may also be altered. For example, in many cancers an increased frequency of infiltrating regulatory $\mathrm{T}$ cells (Tregs) correlates with poor outcome but in colorectal cancer, the infiltrate of Tregs has been associated with both good and poor outcomes [7]. It is therefore important to consider this altered environment and to perform observations at this distinct site when considering tissue targeted immunotherapies. Orthotopic models of colorectal cancer have been described [9-14], but we wished to investigate the ability to modulate the systemic immune response to prevent local tumour growth in the gut. 
Previously, we showed that vaccination with chitosan gel could generate a population of $\mathrm{CD}^{+}$memory $\mathrm{T}$ cells in both peripheral and gut-associated lymphoid sites [15]. Furthermore, vaccination with chitosan gel also provided protection in a subcutaneous tumour challenge model, both prophylactically and therapeutically [15]. However due to the specialised nature of the gut immune system the ability of systemic immunisation to protect against a gut tumour is unknown. We showed that vaccination with chitosan gel was protective in an intracaecal mouse model of cancer, while vaccination with DCs was not. The gel-mediated protection was associated with an increase in antigen specific $\mathrm{T}$ cells and $\mathrm{T}$ cells producing IFN- $\gamma$.

\section{Methods}

Mice

C57BL/6 and OT-I transgenic mice were obtained from the HTRU (University of Otago, Dunedin, NZ) and were bred and housed under specific pathogen free conditions. All experimental procedures were approved by the University of Otago Animal Ethics Committee. No changes in weight or general health (positive or negative) were observed in mice following tumour injection with or without vaccination.

\section{Cell lines}

B16-OVA and B16-luc cell lines were cultured in complete RPMI (with $100 \mu \mathrm{g} / \mathrm{mL}$ Penicillin, $100 \mu \mathrm{g} / \mathrm{mL}$ Streptomycin, $55 \mu \mathrm{M}$ 2-mercaptoethanol, (all from Invitrogen, Carlsbad, USA), $5 \%$ fetal calf serum (PAA laboratories, Morningside, $\mathrm{QLD}, \mathrm{AU})$ at $37{ }^{\circ} \mathrm{C}, 5 \%$ $\mathrm{CO}_{2}$. B16-OVA cells were grown in $5 \%$ complete RPMI with the addition of geneticin (Invitrogen) at $500 \mu \mathrm{g} / \mathrm{mL}$ to prevent loss of ovalbumin protein expression.

\section{Formulation of chitosan hydrogel}

Chitosan (1 \% w/v) (Sigma-Aldrich-Aldrich, St Louis, MO, USA) and methylcellulose (0.5 \% w/v) (SigmaAldrich) were added to $0.05 \mathrm{~mol} / \mathrm{L}$ hydrochloric acid (VWR, Radnor, PA, USA) and stirred at $4{ }^{\circ} \mathrm{C}$ overnight. Glycerol 2-phosphate disodium hydrate (Sigma-Aldrich) was added drop wise to give the solution thermosensitive properties and stirred for a further hour. Ovalbumin protein (OVA; Sigma-Aldrich) and Quil-A (QA; Brenntag Biosector, Denmark) were added for a final concentration of $100 \mu \mathrm{g} / \mathrm{mL}$ and $200 \mu \mathrm{g} / \mathrm{mL}$, respectively, then stirred for a further $30 \mathrm{~min}$ to ensure uniform distribution in solution.

\section{Bone marrow derived dendritic cell generation}

Bone marrow harvested from the leg bones of naive C57BL/6 mice was cultured for 7 days in complete
RPMI and 20 ng/mL GM-CSF (MyBiosource, San Diego, CA, USA) as described [15]. For OVA vaccinations, cells were pulsed with OVA protein overnight on day 5 at a final concentration of $200 \mu \mathrm{g} / \mathrm{mL}$ followed by $1 \mu \mathrm{g} / \mathrm{mL}$ of lipopolysaccharide (Sigma-Aldrich) overnight on day 6 . Dendritic cells were $\mathrm{MHCII}^{+}$and CD80 hi .

\section{Vaccination and adoptive transfer of cells}

Two hundred microlitres of chitosan hydrogel containing both OVA and QA (Gel + OVA) or QA alone (Gel), or $2 \times 10^{5}$ OVA-pulsed DCs (DC + OVA) in $200 \mu \mathrm{l}$ phosphate buffered saline (PBS; $\mathrm{NaCl}$ - Biolab, Australia, $137 \mathrm{mM} ; \mathrm{KCl}$ - VWR, $2.7 \mathrm{mM} ; \mathrm{Na}_{2} \mathrm{HPO}_{4}$ - VWR, $4.3 \mathrm{mM} ; \mathrm{KH}_{2} \mathrm{PO}_{4}$ - Merck, $\left.1.4 \mathrm{mM}\right)$, were injected subcutaneously into the flank of C57BL/6 mice. $2 \times 10^{5}$ naïve OT-I lymphocytes [16] were injected intravenously in $200 \mu \mathrm{l}$ of PBS into the tail vein of mice at the time of vaccination.

\section{Subcutaneous and intracaecal tumour challenge}

Mice were injected with $2 \times 10^{5}$ B16-OVA or B16-luc cells subcutaneously in the flank in $100 \mu \mathrm{L}$ PBS 30 days following vaccination. Surgery for intracaecal injection was carried out according to Tseng et al [17]. Briefly, mice were anaesthetised one at a time using a combination of ketamine, domitor and atropine injected subcutaneously. Pre-operative carporfen was also administered subcutaneously. The abdomen of the mouse was shaved and oil was applied to the eyes. An incision was made through the skin and peritoneum. The caecum was externalised and $25 \mu \mathrm{L}$ PBS containing $1 \times 10^{5}$ cells was injected under a 10x surgical microscope into the subserosa of the caecum. The caecum was repositioned in the abdominal cavity and peritoneum and skin were resutured separately. The mouse was injected with amphoprim antibiotic and antisedan to reverse the anaesthetic effect. Mice were monitored twice daily for 5 days to assess recovery and carporfen and amphoprim were administered twice daily for 2-3 days. All drugs and anaesthetics were distributed by the Animal Welfare Office, University of Otago.

\section{Bioluminescence}

Mice were injected intraperitoneally with $200 \mu \mathrm{L}$ of luciferin (Pure Science, Porirua, New Zealand) and placed in the induction chamber of an isofluorane based gas anaesthetic device. At $5 \mathrm{~min}$ following administration of luciferin, mice were $\mathrm{x}$-rayed for $30 \mathrm{~s}$ and imaged to detect bioluminescence for 5 min. Bruker MI (Bruker, Billerica, MA, USA) and ImageJ (NIH, Bethesda, MD, USA) were used for image capture and analysis. 


\section{Flow cytometry}

Single cell suspensions were resuspended in $1 \mathrm{~mL}$ PBS and incubated with titrated concentrations of Live/Dead Fixable Red Dead Cell Stain (Invitrogen) for $30 \mathrm{~min}$ at $4{ }^{\circ} \mathrm{C}$ in the dark. Samples were washed with FACS buffer (PBS + $0.5 \%$ Fetal Calf Serum and $0.01 \% \mathrm{NaN}_{3}-$ VWR, Radnor, PA, USA) and incubated with titrated concentrations of the following fluorescently labelled anti-mouse antibodies for $10 \mathrm{~min}$ at $4{ }^{\circ} \mathrm{C}$ in the dark: CD8PerCPCy5.5 (53-6.7), CD45.1-BV421 (A20), CD122-PE (5H4; all from BioLegend, San Diego, CA, USA), CD4-APCH7 (GK1.5), CD19-APCH7 (1D3), Va2-APC (B20.1), VB5-FITC (MR9-4), CD44-V500 (1 M7; all from BD Biosciences, Franklin Lakes, NJ, USA). Following this, samples were washed in FACS buffer, fixed in $1 \%$ paraformaldehyde (Sigma-Aldrich) for $30 \mathrm{~min}$ then resuspended in FACS buffer for acquisition on an LSR Fortessa (BD Biosciences) and analysed using FlowJo (Treestar, Ashland, OR, USA). For cytokine detection cells were restimulated with phorbol-12-myristate-13-acetate (PMA) and ionomycin, and brefeldin-A (all from Sigma-Aldrich) was added to samples $2 \mathrm{~h}$ before harvesting. Samples were incubated with IFN- $\gamma$-PE (XMG1.2; BioLegend) antibodies in permeabilisation buffer for $30 \mathrm{~min}$ in the dark at $4{ }^{\circ} \mathrm{C}$ and washed three times in permeabilisation buffer.

\section{Statistical analysis}

GraphPad Prism (GraphPad, La Jolla, CA, USA) was used for all graphs and statistical analysis. Significance was calculated using one-way ANOVA and a Tukey post-hoc test as indicated in figure legends.

\section{Results}

\section{Development of an intra-caecal model of cancer}

Site-specific murine models of cancer are more reflective of human disease. We wished to develop a model that would allow us to make comparisons with human colorectal cancer, particularly in regard to local immune responses. Based on our previous studies showing protection against melanoma using a chitosan hydrogel vaccine delivery formulation, we chose to test immune responses to the vaccine against the same tumour cell line, but injected intra-caecally, to better reflect the local tumour environment of human colorectal cancer. Preliminary studies used a B16-luc cell line to establish the model, as it was easily detectable via bioluminescence in vitro and after subcutaneous injection in vivo. Similar growth kinetics were observed in the B16-OVA cell line as the B16-luc cell line, both in vitro and in vivo (data not shown). In orthotopic mouse models of colorectal cancer metastases are usually minimal, although they are a major component of the human disease. There is evidence that shows B16 cell lines may metastasise to lymph nodes in similar orthotopic models suggesting an advantage for the use of this cell line [18].

Mice were anaesthetised and the caecum was surgically exteriorised following laparotomy so that tumour cells could be injected into the caecal cell wall. Cells were injected into the subserosa of the caecum and mice were monitored during recovery and were imaged at days 10, 15 and 22 following surgery to detect the bioluminescent activity of growing tumour cells (Fig. 1a). At all time points, a bioluminescent signal could be detected in mice (Fig. 1b). This signal was localised to the predicted site of caecal injection and was later verified following euthanasia of mice and direct visualisation of tumours.

These results showed that the intra-caecal mouse model of cancer was viable. Mice recovered well following surgery, with no discernible weight loss, the B16-luc cell line was able to grow in the gut and the bioluminescent signal from the tumour could be detected even at this increased depth compared to subcutaneous tumours. However, B16-luc tumour size did not correlate well with the bioluminescent signal produced (Fig. 1c) and could not be used to quantify growth non-invasively. However the bioluminescent signal did allow for the detection of extensive tumour growth such that mice could be euthanised at an early humane endpoint. Subsequent experiments showed the B16-OVA cell line grew in vivo with similar kinetics and time to endpoint.

\section{Different immune infiltrate in intracaecal compared with subcutaneous tumour microenvironment}

To determine whether the immune infiltration of cells into tumours differed depending on the location of the tumour, mice were injected with B16-luc expressing cells subcutaneously or intracaecally. Twenty days later, tumours and peripheral lymph nodes were excised and labelled with antibodies to surface markers to detect the phenotype of the immune cell infiltrate, including $\mathrm{CD}^{+}$, $\mathrm{CD}^{+}$and $\mathrm{CD}^{+} \mathrm{T}$ cells, $\mathrm{B}$ cells, macrophages and dendritic cells (Additional file 1: Figure S1).

Frequencies of populations of all assessed immune cell types in the lymph nodes were similar between mice receiving intracaecal or subcutaneous tumours (Fig. 2). However, within the tumour, immune cell infiltrates differed. No significant difference was seen in the frequencies of dendritic cells expressing CD11c and macrophages expressing F4/80 between intracaecal and subcutaneous tumours (Fig. 2a, b). A higher frequency of $\mathrm{CD}^{+} \mathrm{T}$ cells was present in the intracaecal tumours than the subcutaneous tumours (Fig. 2c). Interestingly, within the $\mathrm{CD}^{+}$ population, there was no difference in the distribution of $\mathrm{CD}^{+}$and $\mathrm{CD}^{+} \mathrm{T}$ cells between intracaecal and subcutaneous tumours (Fig. 2d, e). This may be due to the presence of $\mathrm{CD}^{+} \mathrm{CD}^{-} \mathrm{CD}^{-} \mathrm{T}$ cell subsets, including 


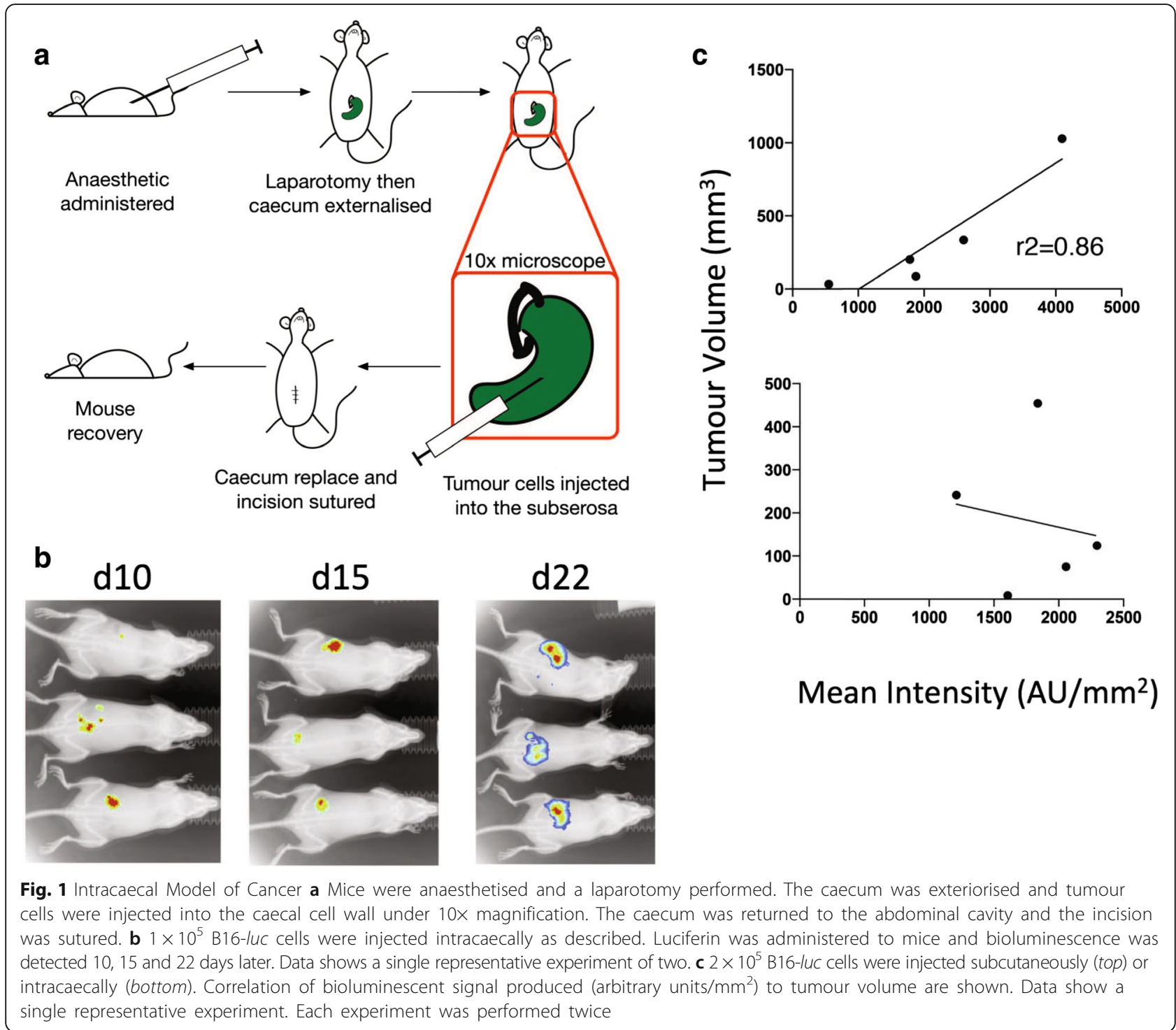

MAIT cells [19] or double negative inflammatory cells [20]. A small but non-significant increase was seen in the frequency of B cells in intracaecal tumours compared to subcutaneous tumours (Fig. 2f). There was no significant difference in tumour size at the time of excision between intra-caecal and subcutaneous tumours (average size $210 \mathrm{~mm}^{3}$ and $143 \mathrm{~mm}^{3}$, respectively), in line with our previous data [15].

The differences in infiltrating lymphocytes between intracaecal and subcutaneous tumours demonstrate that this mouse model of cancer may provide additional insight into immune involvement in cancer of the colon.

\section{Chitosan gel vaccine is protective in a mouse model of colorectal cancer}

We have previously demonstrated that subcutaneous injection with vaccine in a sustained release gel (chitosan gel) generated a population of $\mathrm{CD} 8^{+}$memory $\mathrm{T}$ cells at both peripheral lymphoid sites and gut-associated lymphoid sites [15]. Furthermore, this response protected against a subsequent subcutaneous tumour challenge and was effective in treating established tumours. Due to the presence of $\mathrm{CD}^{+}$memory $\mathrm{T}$ cells in gut-associated lymphoid tissues following vaccination, we hypothesised that vaccination with the sustained release gel would also provide protection against gut tumours. To test this hypothesis, the intra-caecal mouse model of cancer was used to challenge vaccinated mice.

Mice were vaccinated subcutaneously with vaccine (OVA and the adjuvant Quil A) in chitosan gel (Gel + OVA), with gel and Quil A but no antigen (Gel), with a control immune-based vaccine of activated DC pulsed with OVA (DC + OVA) or were unvaccinated. No change in weight, health or survival was observed following 

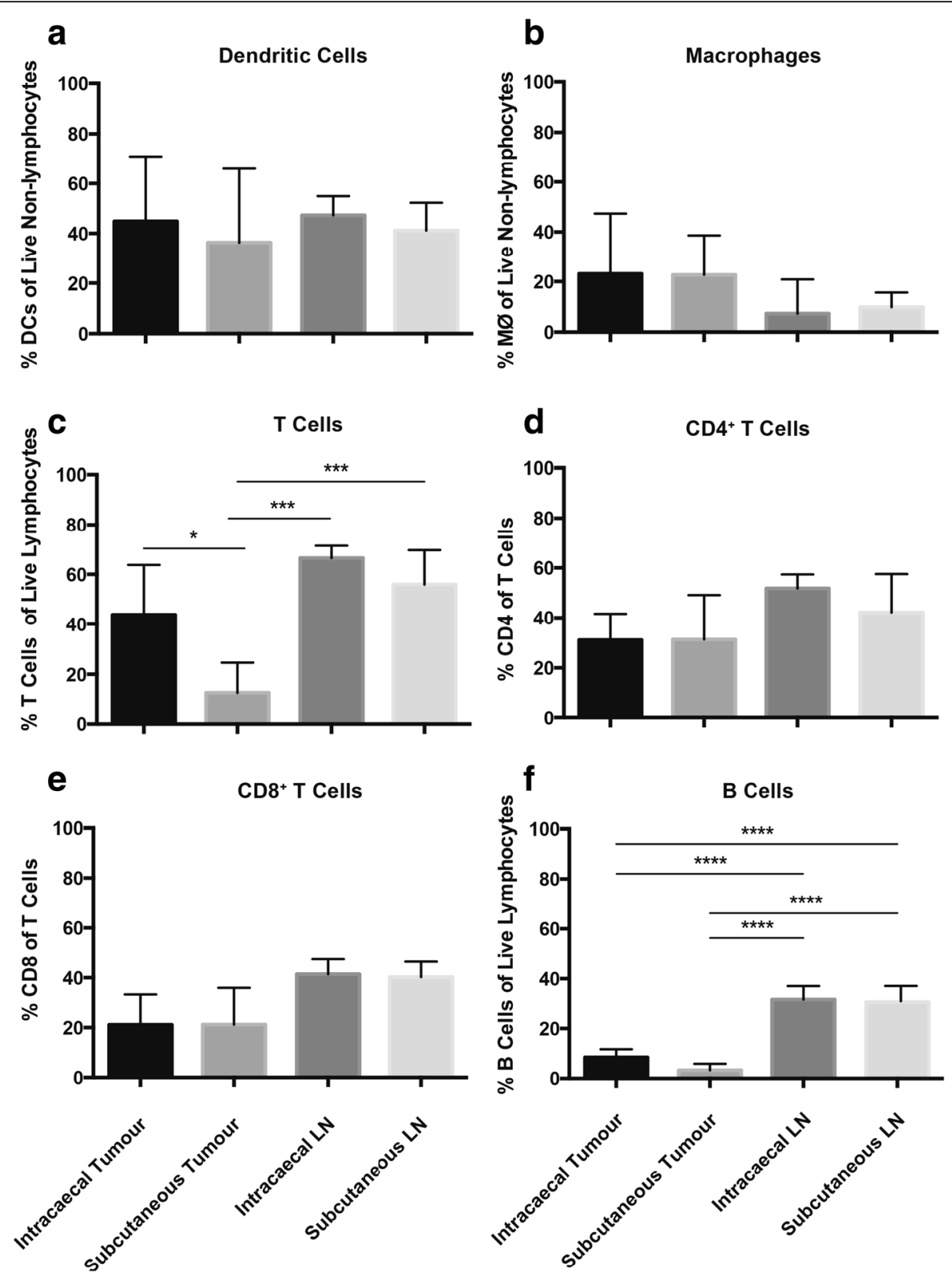

Fig. 2 Immune infiltrate can be detected in mice challenged with B16-luc a Percentage CD11 $\mathbf{c}^{+}$of live non-lymphocytes (dendritic cells), b percentage $\mathrm{F}_{480^{+}}$of non-lymphocytes (macrophages), c percentage $\mathrm{CD}^{+}$of lymphocytes (T cells), $\mathbf{d}$ percentage $\mathrm{CD}^{+}$of $\mathrm{T}$ cells, e percentage $\mathrm{CD} 8^{+}$of $\mathrm{T}$ cells and $\mathbf{f}$ percentage CD19+ of lymphocytes (B cells) in tumours or draining lymph nodes. Data are shown as mean \pm standard deviation, $n=4-5$, representative of two individual experiments. One-way ANOVA with Turkey post-hoc test was performed. ${ }^{*} P<0.05,{ }^{*} P<0.01$, ${ }^{* * *} P<0.001,{ }^{* * *} P<0.0001$

vaccination, consistent with previous results [15]. All mice received adoptive transfer of OT-I lymphocytes as described previously in order to accurately quantify antigen-specific memory responses [15]. Thirty to 34 days later, mice were injected intracaecally with B16-OVA. Mice were euthanised at the pre-determined time point of 3 weeks based on tumour growth determined in Fig. 1 (and data not shown); hence no survival data are available.
Tumours developed in all of the mice vaccinated with Gel, and in $90 \%$ of mice vaccinated with DC + OVA. Only $50 \%$ of the mice vaccinated with Gel + OVA developed tumours (Fig. 3a). Tumours in unimmunised mice and in mice immunised with the dendritic cell vaccine or with gel without antigen were larger than those vaccinated with gel plus antigen (Fig. 3b). These data indicate that vaccination with chitosan gel is superior to vaccination with a $D C$ vaccine in this model. 

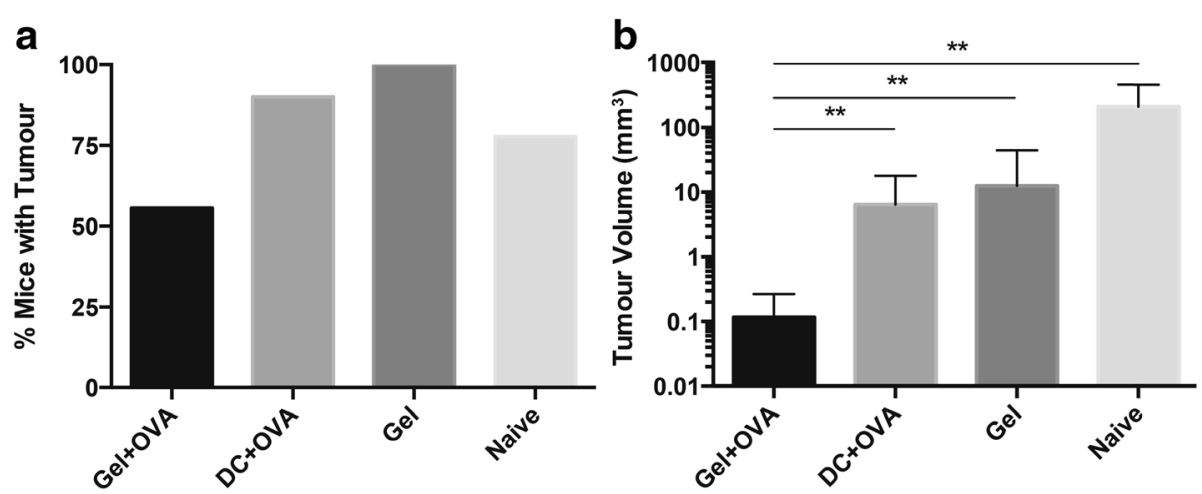

Fig. 3 Vaccination with a sustained release gel reduces the frequency of tumour development. Mice received adoptive transfer of OT-I lymphocytes and were not vaccinated or were vaccinated with antigen in a chitosan gel (Gel + OVA), the gel alone (Gel) or with antigen pulsed-DC (DC + OVA) then challenged intracaecally with B16-OVA 30 days later. a Percentage of mice with visible tumours and $\mathbf{b}$ mean volume of tumours at day 21. Data are shown as mean \pm standard deviation, Data pooled from two individual experiments, $n=8-9$. One-way ANOVA with Tukey post-hoc test was performed. ${ }^{* *} P<0.01$

\section{Chitosan gel vaccine generates antigen specific memory} $\mathrm{CD}^{+} \mathrm{T}$ cells in gut-associated tissue

Fifty one to 54 days following vaccination with Gel + OVA, DC + OVA or Gel (21 days after intracaecal tumour challenge with B16-OVA cells) peripheral lymph nodes, spleens, mesenteric lymph nodes and Peyer's patches were excised. The frequencies of antigen-specific $\left(\mathrm{V} \alpha 2^{+} \mathrm{V} \beta 5^{+}\right)$and memory $\mathrm{T}$ cells were examined (Additional file 2: Figure S2). As many tumours, particularly in mice vaccinated with Gel + OVA, were too small or non-existent at the designated time point to retrieve sufficient material for analysis, tumours themselves were not analysed.

Previously, we have shown the Gel + OVA vaccination results in a higher frequency of antigen-specific as well as memory antigen-specific $\mathrm{CD} 8+\mathrm{T}$ cells (prior to tumour challenge) than Gel only or DC-OVA vaccination [15]. To determine whether the higher cell number was consistent after tumour challenge and potentially mediating tumour protection, we measured the frequency of antigen-specific cells in mice following intra-caecal tumour injection. There was a significantly higher frequency of $\mathrm{V \alpha}^{+} \mathrm{V} \beta 5^{+}$(OVA-specific) $\mathrm{CD}^{+} \mathrm{T}$ cells in the peripheral lymph nodes and spleens of mice vaccinated with Gel + OVA than with other vaccines (Fig. 4a, b). In the gut-associated lymphoid tissues, Peyer's patches and mesenteric lymph nodes, no significant difference was seen in the frequency of $\mathrm{V} \alpha 2^{+} \mathrm{V} \beta 5^{+}$ $\mathrm{CD}^{+} \mathrm{T}$ cells seen at each site (data not shown). The frequency of $\mathrm{CD} 122^{+} \mathrm{CD} 44^{+}$memory phenotype [21] cells in the OVA-specific $\mathrm{CD}^{+} \mathrm{T}$ cell population was significantly higher in those mice vaccinated with Gel + OVA compared to all other treatments in lymph nodes and spleen (Fig. 4c, d). The absolute number of cells was similar to the frequency of cells in each vaccination group (Additional file 3: Figure S3). Together, these data demonstrate that mice vaccinated with Gel + OVA acquired high frequencies of OVA-specific $\mathrm{CD}^{+}$effector and memory $\mathrm{T}$ cells compared to mice receiving other vaccines; similar to results seen in the melanoma model [15]. Taken together, these data indicate that chitosan gel vaccination increases the frequency of memory $\mathrm{CD} 8+\mathrm{T}$ cells and this results in enhanced protection compared to other vaccines in both intra-caecal and subcutaneous tumour challenge.

\section{Protection by chitosan gel vaccine is associated with IFN- $\gamma$ producing T cells}

To determine the function of antigen-specific memory $\mathrm{CD}^{+} \mathrm{T}$ cells generated following vaccination, production of IFN- $\gamma$ was measured in cells extracted from the spleens and Peyer's patches of the vaccinated mice and from unvaccinated controls 3 weeks after intracaecal challenge with B16-OVA cells. To mimic studies of the immune response in human cancer [22], the extracted cells were incubated in the presence of PMA and ionomycin for $4 \mathrm{~h}$ and were analysed for expression of surface markers to detect $\mathrm{CD}^{+}$and $\mathrm{CD}^{+}{ }^{+} \mathrm{T}$ cells, as well as $\mathrm{V} \alpha 2^{+} \mathrm{V} \beta 5^{+}$to detect antigen-specific $\mathrm{T}$ cells, in conjunction with intracellular IFN- $\gamma$.

All immunised mice had a higher frequency of IFN $-\gamma^{+}$ $\mathrm{CD}^{+} \mathrm{T}$ cells in the spleen, compared to unvaccinated mice (Fig. 5a, b), with the frequency of IFN $-\gamma^{+} \mathrm{CD}^{+} \mathrm{T}$ cells in mice immunised with Gel + OVA being the highest of vaccine groups. Within the $\mathrm{CD}^{+} \mathrm{T}$ cell compartment, a significant increase in the frequency of IFN- $\gamma$ producing cells was found in cells isolated from the spleen of Gel + OVA vaccinated mice (Fig. 5c, d), and not the other groups, when compared to unvaccinated mice. A significant increase was seen in the frequency and number of IFN- $\gamma$ producing $\mathrm{V} \alpha 2^{+} \mathrm{V} \beta 5^{+}$ $\mathrm{CD} 8^{+} \mathrm{T}$ cells in the spleens of mice vaccinated with 

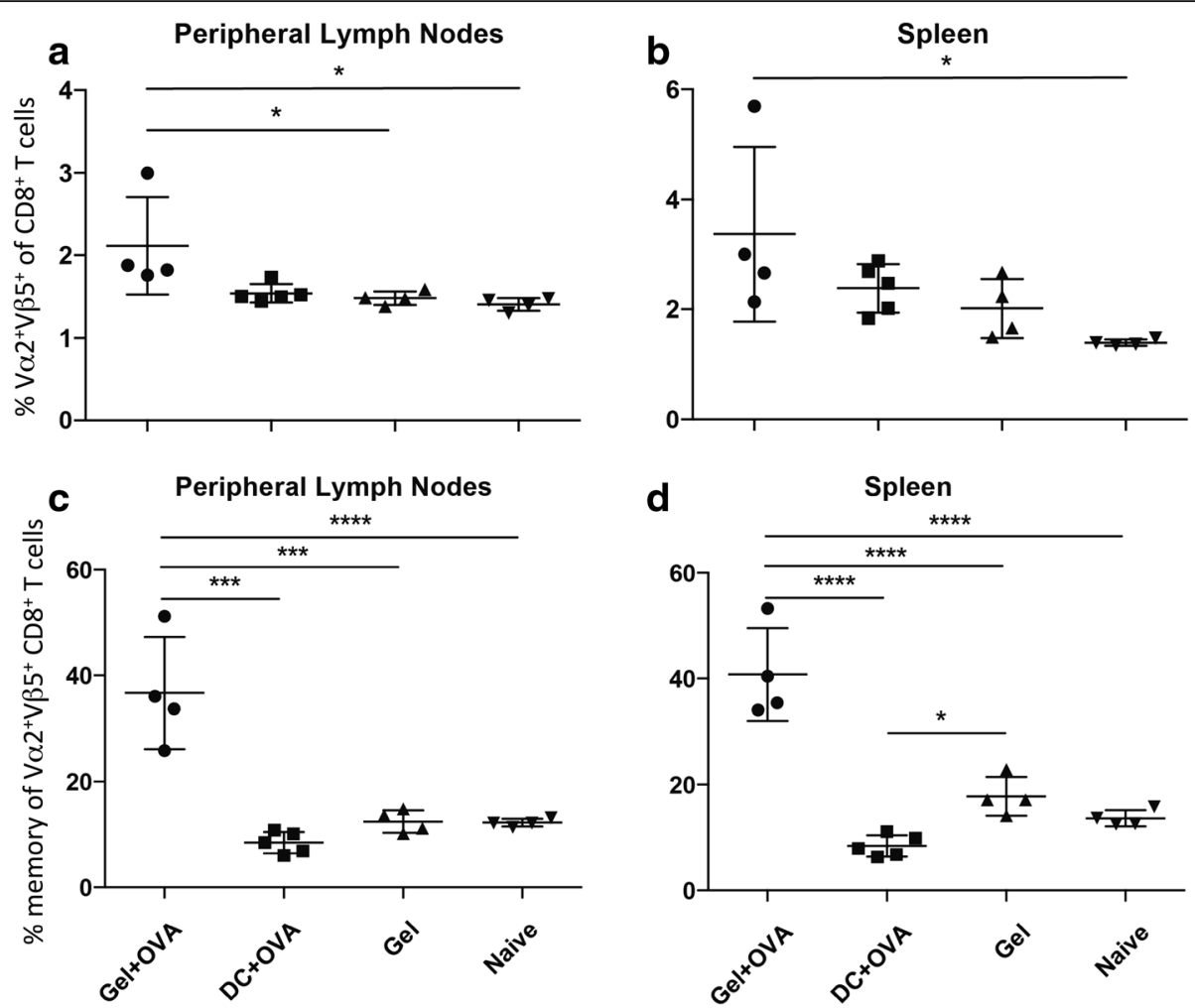

Fig. 4 Vaccination with vaccine in a chitosan gel increases the frequency of OVA-specific CD8 ${ }^{+} T$ cells post challenge with tumour. Mice received adoptive transfer of OT-I lymphocytes and were vaccinated with vaccine in a chitosan gel (Gel + OVA), the gel alone (Gel) or with vaccine pulsed-DC (DC + OVA) then challenged intracaecally with B16-OVA 30 days later. $\mathbf{a}$, $\mathbf{b}$ Percentage of $\mathrm{Va}^{+} \mathrm{V} \beta 5^{+} \mathrm{T}$ cells of $C D 8^{+} \mathrm{T}$ cells is shown in peripheral lymph nodes (a) and spleens (b) at day 21. c, d Percentage of $\mathrm{CD} 122^{+} \mathrm{CD} 44^{+}$of $\mathrm{Va2}^{+} \mathrm{V} \beta 5^{+} \mathrm{CD} 8^{+} \mathrm{T}$ cells is shown in peripheral lymph nodes (c) and spleens (d) at 21 days following challenge. Data are shown as mean \pm standard deviation, $n=4-5$, representative of two individual experiments. One-way ANOVA with Tukey post-hoc test was performed. ${ }^{*} P<0.05,{ }^{* *} P<0.01,{ }^{* * *} P<0.001,{ }^{* * *} P<0.0001$

Gel + OVA and a smaller, but still significant, increase in IFN- $\gamma$ producing $\mathrm{V} \alpha 2^{+} \mathrm{V} \beta 5^{+} \mathrm{CD} 8^{+} \mathrm{T}$ cells was also seen in the spleens of mice immunised with Gel alone (Fig. 5e, f). No difference was seen in IFN- $\gamma$-producing total memory $\mathrm{T}$ cell populations between groups (data not shown).

\section{Discussion}

Colorectal cancer $(\mathrm{CRC})$ is the third most common cancer in men and the second in women worldwide [1]. In order to evaluate new immune therapies in a preclinical setting, appropriate animal models are required. Here we have described an intra-caecal model of colorectal cancer in mice and shown that immune modulation of the systemic response can result in tumour protection associated with antigen specific $\mathrm{T}$ cells producing IFN- $\gamma$, consistent with the human disease $[4,22]$.

Interestingly we also demonstrated that biological location has an effect on the makeup of immune infiltrate into a tumour. It is well known that in many solid tumours infiltration of high numbers of T cells correlates with improved prognosis [4] and it has been reported that both $\mathrm{B}$ and $\mathrm{T}$ cells are important in human colorectal cancer [23]. Interestingly, in this study we found a difference in $\mathrm{CD} 3+\mathrm{T}$ cell frequencies between intra-caecal and subcutaneous tumours, but no difference in the frequencies of $\mathrm{CD} 4+$ or $\mathrm{CD} 8+\mathrm{T}$ cells. There are many subsets of $\mathrm{T}$ cells that may be reflected in this result, including pro-inflammatory "pathogenic" $\mathrm{T}$ cells [24], naturally occurring $\mathrm{T}$ cells that have downregulated co-receptor expression [20, 25], NKT cells and MAIT cells [19], $\gamma \delta$ T cells [26], and T cells in the context of immune deficiency [27]; all of which may be involved in anti-tumour immune responses, especially in the gut. Based on these results, further experiments should include an expanded panel of molecules to determine which of these $\mathrm{CD}^{+}$populations may have a significant effect on the local tumour immune response.

For mucosal immunity, priming of T cells by DCs in gut associated lymphoid tissues preferentially up-regulates mucosal homing receptors on those cells; hence the rationale for testing DC-OVA as a vaccine control. In the Peyer's patches and mesenteric lymph nodes, $\mathrm{CD}_{103^{+}}$ DCs cause up-regulation of CCR9 and $\alpha 4 \beta 7$ on lymphocytes, thus allowing them to migrate to gut mucosa [28-30]. Mucosal vaccines typically take advantage of 

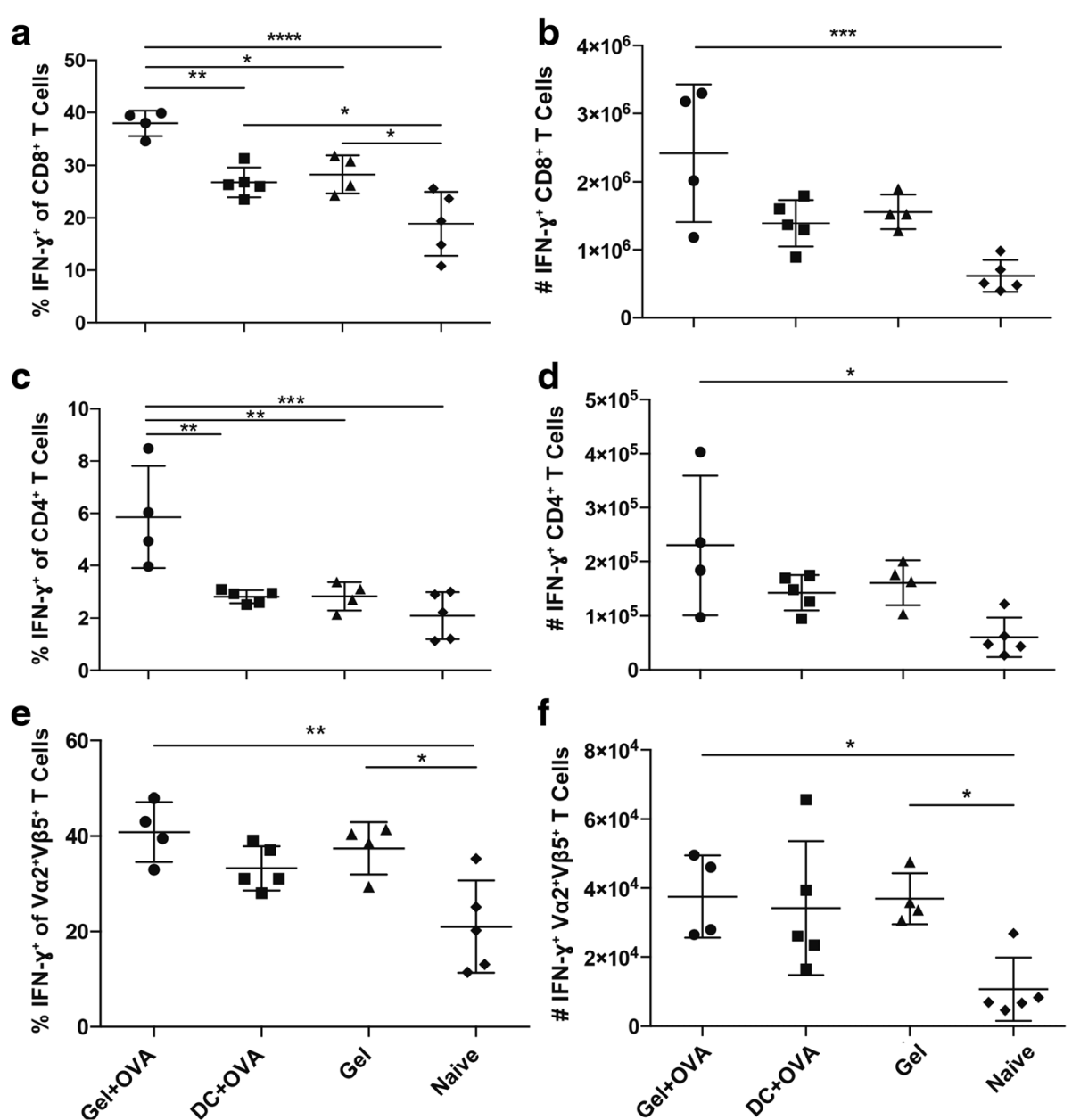

Fig. 5 Vaccination with Gel + OVA increases cytokine production in the spleen. Mice received adoptive transfer of OT-I lymphocytes and were not vaccinated or were vaccinated with vaccine in a chitosan gel (Gel + OVA), the gel alone (Gel) or with vaccine pulsed-DC (DC + OVA) then challenged intracaecally with B16-OVA 30 days later. Percentage $(\mathbf{a}, \mathbf{c}, \mathbf{e})$ and number $(\mathbf{b}, \mathbf{d}, \mathbf{f})$ of IFN- $\gamma^{+} \mathrm{CD} 8^{+} \mathrm{T}$ cells $(\mathbf{a}, \mathbf{b})$, IFN- $\gamma^{+}$ $\mathrm{CD}^{+} \mathrm{T}$ cells $(\mathbf{c}, \mathbf{d}), \mathrm{IFN}-\gamma^{+} \mathrm{Va} 2 \mathrm{~V} \beta 5^{+} \mathrm{CD}^{+} \mathrm{T}$ cells $(\mathbf{e}, \mathbf{f})$. All data shown are from spleen cells restimulated with PMA/ionomycin for $4 \mathrm{~h}$, 21 days following challenge. Data are shown as mean \pm standard deviation, $n=4-5$, representative of two individual experiments. One-way ANOVA with Tukey post-hoc test was performed. ${ }^{*} P<0.05,{ }^{* *} P<0.01,{ }^{*}{ }^{*} P<0.001,{ }^{* * *} P<0.0001$

this mechanism through administration at sites allowing antigen presentation to occur in gut associated lymphoid tissue. However, there are difficulties in developing oral peptide and protein based vaccines in terms of delivery of antigen in an immunogenic form to gut-associated lymphoid tissue. In the intra-caecal mouse model of cancer, the sustained release vaccine, but not a DC vaccine, provided protection. This protection was associated with an increased frequency of tumour specific $\mathrm{T}$ cells at peripheral lymphoid but not gut-associated lymphoid tissues. However, the absolute number of cells present in Peyer's patches and mesenteric lymph nodes was low and it is possible that a later time-point is needed to detect differences. The frequency of tumour specific memory $\mathrm{CD} 8{ }^{+} \mathrm{CD} 122^{+} \mathrm{CD} 44^{+} \mathrm{T}$ cells was significantly higher in mice vaccinated with the sustained release vaccine in peripheral lymphoid sites sampled consistent with our previous data prior to tumour challenge [15]. Here, we show that this increase is maintained after tumour challenge and is likely to be a correlate of protection. Further we show that the frequency of cytokine producing (IFN- $\gamma) \mathrm{CD}^{+}$and $\mathrm{CD} 4^{+} \mathrm{T}$ cells detected in the spleen was higher in Gel + OVA vaccinated mice than others, implying an IFN $\gamma$-mediated anti-tumour effect.

It is unclear if the tumours generated in this model are susceptible to systemic immunity or if gut-associated immune protection is required. Vaccination with the sustained release gel generated a population of antigenspecific $\mathrm{CD}^{+} \mathrm{T}$ cells in both Peyer's patches and mesenteric lymph nodes, two gut-associated lymphoid sites, but this vaccine also stimulated stronger systemic responses than did the DC vaccine [15]. Therefore it is 
also possible that protection was conferred through effector memory $\mathrm{T}$ cells. While not mucosa specific, these cells are able to track through multiple tissues [31]. An effective effector memory $\mathrm{T}$ cell $\left(\mathrm{T}_{\mathrm{em}}\right)$ population generated through vaccination with a sustained release gel may provide protection in multiple different biological locations through the body.

The magnitude of the immune response generated by the DC vaccine was in general smaller as compared to the gel vaccine, similar to subcutaneous vaccination [15]. However the increased production of IFN- $\gamma$ by OVAspecific $\mathrm{CD}^{+} \mathrm{T}$ cells in mice vaccinated with the gel compared to those vaccinated with the DC vaccine indicated that these cells could also have a functional difference. In preliminary experiments we also showed an increased frequency of $\mathrm{IL}-2^{+} \mathrm{OVA}-$ specific $\mathrm{CD} 8^{+}$memory $T$ cells in mice vaccinated with the gel vaccine compared to other vaccine groups (data not shown). It is possible that these cells may also have an increased capacity for proliferation and survival. This would allow for development of a more robust secondary recall population of $\mathrm{CD}^{+}$memory $\mathrm{T}$ cells upon tumour challenge.

These results also address a potential concern with the use of sustained release vaccines, namely that sustained release of vaccine may result in immune exhaustion rather than the development of effector or memory populations [32]. It is likely that the kinetics of release as well as the strength of the immune stimulation will impact on the type of response generated therefore caution should be taken when developing sustained release formulations in order to ensure that such parameters are optimised.

Interestingly the gel itself, in the absence of antigen, induced an increase in the frequency and number of antigen specific IFN- $\gamma$ producing $\mathrm{T}$ cells in the spleens of mice challenged with OVA expressing tumour cells. Chitosan has been reported to have adjuvant activity $[33,34]$ and the gel, while not containing any antigen, was also loaded with the potent Th1 adjuvant Quil A [35]. The gel would have created an inflammatory depot that may have non-specifically boosted immune reactivity, much the same way the CpG have been used as a therapy to boost anti-tumor immunity [36]. Destruction of the tumour and release of OVA (a foreign antigen) by dying tumours would then have led to the development of some degree of antigen specific immunity. Mice immunised with the gel only did show some slight evidence of anti-tumor immunity. However as with the CpG studies, inclusion of a tumour antigen with the therapy increases the efficacy of the response [36].

The B16 cell line used for intracaecal challenge is a melanoma cell line. While this allowed for direct comparison to subcutaneous B16 challenge ref, in this mouse model of colorectal cancer it may be beneficial to use a mouse colorectal cancer cell line. Further experiments using the CT26 colorectal cancer cell line expressing an endogenous peptide $[37,38]$ or a MC38 colorectal cancer cell line expressing OVA [39] may provide more insight into the disease by providing more accuracy to the model system.

\section{Conclusions}

In a clinical setting, cancer is generally treated therapeutically. In this research, mice were vaccinated prophylactically in order to assess the memory populations of $\mathrm{T}$ cells generated. Although vaccination with the sustained release proved successful in this setting, further work is required to find whether the same is true when used as a therapy as shown in a subcutaneous model [15]. If this treatment were to be effective, it would further implicate chitosan gel as a potential anti-cancer vaccine strategy. The ability of vaccination with a sustained release vaccine to work therapeutically would rely on the ability of the activated immune cells to overcome the immunosuppressive effect of the tumour. It is likely this approach would be combined with others targeted at overcoming tumour induced immune suppression in order to achieve maximal therapeutic benefit.

\section{Additional files}

\begin{abstract}
Additional file 1: Figure S1. Flow cytometry gating for identification of tumour immune cell infiltrates. Singlets were identified by gating with FSC- $\mathrm{H}$ versus FSC-A then SSC-H versus SSC-A. Live cells had low levels of Live/Dead dye. Lymphocytes and large cells were identified based on SSC-A and FSC-A. F4/80 expression was used to designate macrophages within the large cell gate and CD11c was used as an identifying marker of dendritic cells. CD19 was used to identify B cells within the lymphocyte gate and CD3 was used to identify T cells. CD8 ${ }^{+}$and $\mathrm{CD}^{+} \mathrm{T}$ cells were identified within the CD3 gate. (PDF $1568 \mathrm{~kb}$ )
\end{abstract}

Additional file 2: Figure S2. Flow cytometry gating for identification of cytokine producing cells following vaccination and subcutaneous tumour challenge. Singlets were identified by gating with FSC-H versus FSC-A then SSC-H versus SSC-A. Live cells had low levels of Live/Dead dye and lymphocytes were identified based on SSC-A and FSC-A. CD8 ${ }^{+} \mathrm{T}$ cells were those that expressed CD8 and CD4 ${ }^{+} \mathrm{T}$ cells were those expressing CD4. Va2, V 35 double positive cells were identified within the CD8 gate and those expressing CD122 and CD44 were defined as memory cells. IFN- $\gamma$ production was analysed in $\mathrm{CD}^{+} \mathrm{T}$ cells, CD4 ${ }^{+} \mathrm{T}$ cells, $\mathrm{Va}^{+} \mathrm{V} \beta 5^{+}$cells and $\mathrm{CD} 122^{+} \mathrm{CD} 44^{+}$memory cells. (PDF $1292 \mathrm{~kb}$ )

Additional file 3: Figure S3. Vaccination with vaccine in a chitosan gel increases the absolute cell number of OVA-specific $C D 8^{+} \mathrm{T}$ cells post challenge with tumour. Mice received adoptive transfer of OT-I lymphocytes and were vaccinated with vaccine in a chitosan gel (Gel + OVA), the gel alone (Gel) or with vaccine pulsed-DC (DC + OVA) then challenged intra-caecally with B16-OVA 30 days later. (A, B) Number of $\mathrm{VaZ}^{+} \mathrm{V} \beta 5^{+} \mathrm{T}$ cells of $\mathrm{CD} 8^{+} \mathrm{T}$ cells is shown in peripheral lymph nodes (A) and spleens (B) at day 21. (C, D) Number of CD122 ${ }^{+} \mathrm{CD} 44^{+}$of $\mathrm{Va} 2^{+} \mathrm{V} \beta 5^{+}$ $\mathrm{CD}^{+} \mathrm{T}$ cells is shown in peripheral lymph nodes (C) and spleens (D) at 21 days following challenge. Data are shown as mean \pm standard deviation, $n=4-5$, representative of two individual experiments. One-way ANOVA with Tukey post-hoc test was performed. ${ }^{* *} P<0.01$. (EPS $1138 \mathrm{~kb}$ ) 


\section{Funding}

This work was supported by the Genesis Oncology Trust and Lotteries Health New Zealand. AJH was supported by a University of Otago PhD scholarship. The funding bodies were not involved in the design of the study and collection, analysis, and interpretation of data or in writing the manuscript should be declared.

\section{Availability of data and materials}

The datasets during and/or analysed during the current study available from the corresponding author on reasonable request.

\section{Authors' contributions}

AJH designed, performed and analysed experiments. AG and GMB provided assistance with experiments. SH provided chitosan gel and designed experiments. RK was responsible for overall project, designed and analysed experiments. AJH, SH and RK wrote the manuscript. All authors read and approved the final manuscript.

\section{Competing interests}

The authors declare that they have no competing interests.

\section{Consent for publication}

Not applicable.

\section{Ethics approval}

All experimental procedures were approved by the University of Otago Animal Ethics Committee.

\section{Author details}

'Department of Microbiology and Immunology, Otago School of Medical Sciences, University of Otago, PO Box 56, Dunedin 9054, New Zealand.

${ }^{2}$ School of Pharmacy, University of Otago, Dunedin, New Zealand.

\section{Received: 2 July 2016 Accepted: 13 October 2016}

\section{Published online: 18 October 2016}

\section{References}

1. GLOBOCAN: GLOBOCAN 2012: Estimated cancer incidence, mortality and prevalence worldwide in 2012. Lyon, France: International Agency for Research on Cancer and World Health Organization; 2012.

2. Grady WM. Genetic testing for high-risk colon cancer patients. Gastroenterol. 2003;124(6):1574-94.

3. Triantafillidis JK, Nasioulas G, Kosmidis PA. Colorectal cancer and inflammatory bowel disease: epidemiology, risk factors, mechanisms of carcinogenesis and prevention strategies. Anticancer Res. 2009;29(7):2727-37.

4. Galon J, Costes A, Sanchez-Cabo F, Kirilovsky A, Mlecnik B, Lagorce-Pages C, Tosolini M, Camus M, Berger A, Wind P, et al. Type, density, and location of immune cells within human colorectal tumors predict clinical outcome. Science. 2006:313(5795):1960-4.

5. Erreni M, Mantovani A, Allavena P. Tumor-associated macrophages (TAM) and inflammation in colorectal cancer. Cancer Microenviron. 2011;4(2):141-54.

6. Frey DM, Droeser RA, Viehl CT, Zlobec I, Lugli A, Zingg U, Oertli D, Kettelhack C, Terracciano L, Tornillo L. High frequency of tumor-infiltrating FOXP3(+) regulatory T cells predicts improved survival in mismatch repairproficient colorectal cancer patients. Int J Cancer. 2010;126(11):2635-43.

7. Ladoire S, Martin F, Ghiringhelli F. Prognostic role of FOXP3+ regulatory T cells infiltrating human carcinomas: the paradox of colorectal cancer. Cancer Immunol Immunother. 2011:60(7):909-18.

8. Sinicrope FA, Rego RL, Ansell SM, Knutson KL, Foster NR, Sargent DJ. Intraepithelial effector (CD3+)/regulatory (FoxP3+) T-cell ratio predicts a clinical outcome of human colon carcinoma. Gastroenterol. 2009;137(4):1270-9.

9. Endo T, Toda M, Watanabe M, lizuka Y, Kubota T, Kitajima M, Kawakami Y. In situ cancer vaccination with a replication-conditional HSV for the treatment of liver metastasis of colon cancer. Cancer Gene Ther. 2002;9(2):142-8.

10. Kruse J, von Bernstorff W, Evert K, Albers N, Hadlich S, Hagemann S, Gunther C, van Rooijen N, Heidecke CD, Partecke LI. Macrophages promote tumour growth and liver metastasis in an orthotopic syngeneic mouse model of colon cancer. Int J Colorectal Dis. 2013;28(10):1337-49.
11. Zigmond E, Halpern Z, Elinav E, Brazowski E, Jung S, Varol C. Utilization of murine colonoscopy for orthotopic implantation of colorectal cancer. PLoS One. 2011;6(12), e28858.

12. Devaud C, Westwood JA, John LB, Flynn JK, Paquet-Fifield S, Duong CP, Yong CS, Pegram HJ, Stacker SA, Achen MG, et al. Tissues in different anatomical sites can sculpt and vary the tumor microenvironment to affect responses to therapy. Mol Ther. 2014;22(1):18-27.

13. Alencar H, King R, Funovics M, Stout C, Weissleder R, Mahmood U. A novel mouse model for segmental orthotopic colon cancer. Int J Cancer. 2005;117(3):335-9.

14. Wilmanns C, Fan D, O'Brian CA, Bucana CD, Fidler IJ. Orthotopic and ectopic organ environments differentially influence the sensitivity of murine colon carcinoma cells to doxorubicin and 5-fluorouracil. Int J Cancer. 1992;52(1):98-104

15. Highton AJ, Kojarunchitt T, Girardin A, Hook S, Kemp RA. Chitosan hydrogel vaccine generates protective CD8 T cell memory against mouse melanoma. Immunol Cell Biol. 2015:93(7):634-40.

16. Hogquist KA, Jameson SC, Heath WR, Howard JL, Bevan MJ, Carbone FR. T cell receptor antagonist peptides induce positive selection. Cell. 1994;76(1):17-27.

17. Tseng W, Leong $X$, Engleman E. Orthotopic mouse model of colorectal cancer. J Vis Exp. 2007;10:484

18. Kashtan H, Rabau M, Mullen JB, Wong AH, Roder JC, Shpitz B, Stern HS, Gallinger S. Intra-rectal injection of tumour cells: a novel animal model of rectal cancer. Surg Oncol. 1992;1(3):251-6.

19. Treiner E, Lantz O. CD1d- and MR1-restricted invariant T cells: of mice and men. Curr Opin Immunol. 2006;18(5):519-26.

20. Crispin JC, Tsokos GC. Human TCR-alpha beta + CD4-CD8- T cells can derive from CD8+ T cells and display an inflammatory effector phenotype. J Immunol. 2009:183(7):4675-81.

21. Buentke E, Mathiot A, Tolaini M, Di Santo J, Zamoyska R, Seddon B. Do CD8 effector cells need IL-7R expression to become resting memory cells? Blood. 2006;108(6):1949-56

22. Girardin A, McCall J, Black MA, Edwards F, Phillips V, Taylor ES, Reeve AE, Kemp RA. Inflammatory and regulatory T cells contribute to a unique immune microenvironment in tumor tissue of colorectal cancer patients. Int J Cancer. 2013;132(8):1842-50.

23. Bindea G, Mlecnik B, Tosolini M, Kirilovsky A, Waldner M, Obenauf AC, Angell $H$, Fredriksen $T$, Lafontaine $L$, Berger $A$, et al. Spatiotemporal dynamics of intratumoral immune cells reveal the immune landscape in human cancer. Immunity. 2013;39(4):782-95.

24. D'Acquisto F, Crompton T. CD3 + CD4-CD8- (double negative) T cells: saviours or villains of the immune response? Biochem Pharmacol. 2011;82(4):333-40.

25. Martina MN, Noel S, Saxena A, Rabb H, Hamad AR. Double negative (DN) alphabeta T cells: misperception and overdue recognition. Immunol Cell Biol. 2015:93(3):305-10

26. Bender A, Kabelitz D. CD4-CD8- human T cells: phenotypic heterogeneity and activation requirements of freshly isolated "double-negative" $T$ cells. Cell Immunol. 1990;128(2):542-54

27. Bernardo I, Mancebo E, Aguilo I, Anel A, Allende LM, Guerra-Vales JM, Ruiz-Contreras J, Serrano A, Talayero P, de la Calle O, et al. Phenotypic and functional evaluation of CD3 + CD4-CD8- T cells in human CD8 immunodeficiency. Haematologica. 2011;96(8):1195-203.

28. Hammerschmidt SI, Ahrendt M, Bode U, Wahl B, Kremmer E, Forster R, Pabst O. Stromal mesenteric lymph node cells are essential for the generation of gut-homing T cells in vivo. J Exp Med. 2008;205(11):2483-90.

29. Iwata M, Hirakiyama A, Eshima Y, Kagechika H, Kato C, Song SY. Retinoic acid imprints gut-homing specificity on T cells. Immunity. 2004;21(4):527-38

30. Mora JR, Bono MR, Manjunath N, Weninger W, Cavanagh LL, Rosemblatt M, Von Andrian UH. Selective imprinting of gut-homing T cells by Peyer's patch dendritic cells. Nature. 2003;424(6944):88-93.

31. Zhang Q, Lakkis FG. Memory T cell migration. Front Immunol. 2015;6:504.

32. Hailemichael $Y$, Dai Z, Jaffarzad N, Ye Y, Medina MA, Huang XF, Dorta-Estremera SM, Greeley NR, Nitti G, Peng W, et al. Persistent antigen at vaccination sites induces tumor-specific CD8(+) T cell sequestration, dysfunction and deletion. Nat Med. 2013;19(4):465-72.

33. Chenite A, Chaput C, Wang D, Combes C, Buschmann MD, Hoemann CD, Leroux JC, Atkinson BL, Binette F, Selmani A. Novel injectable neutral solutions of chitosan form biodegradable gels in situ. Biomaterials. 2000;21(21):2155-61. 
34. Tang YW X, Yan L, Lei M, Du Y, Kennedy JF, Knill CJ. Production and characterisation of novel injectable chitosan/methylcellulose/salt blend hydrogels with potential application as tissue engineering scaffolds. Carbohydr Polym. 2010;82:833-41.

35. Sun HX, Xie Y, Ye YP. Advances in saponin-based adjuvants. Vaccine. 2009;27(12):1787-96.

36. Krieg AM. CpG still rocks! Update on an accidental drug. Nucleic Acid Ther. 2012;22(2):77-89.

37. Huang AY, Gulden PH, Woods AS, Thomas MC, Tong CD, Wang W, Engelhard VH, Pasternack G, Cotter R, Hunt D, et al. The immunodominant major histocompatibility complex class I-restricted antigen of a murine colon tumor derives from an endogenous retroviral gene product. Proc Natl Acad Sci U S A. 1996;93(18):9730-5.

38. Jordan KR, McMahan RH, Kemmler CB, Kappler JW, Slansky JE. Peptide vaccines prevent tumor growth by activating $T$ cells that respond to native tumor antigens. Proc Natl Acad Sci U S A. 2010;107(10):4652-7.

39. Gilfillan S, Chan CJ, Cella M, Haynes NM, Rapaport AS, Boles KS, Andrews DM, Smyth MJ, Colonna M. DNAM-1 promotes activation of cytotoxic lymphocytes by nonprofessional antigen-presenting cells and tumors. J Exp Med. 2008;205(13):2965-73.

Submit your next manuscript to BioMed Central and we will help you at every step:

- We accept pre-submission inquiries

- Our selector tool helps you to find the most relevant journal

- We provide round the clock customer support

- Convenient online submission

- Thorough peer review

- Inclusion in PubMed and all major indexing services

- Maximum visibility for your research

Submit your manuscript at www.biomedcentral.com/submit
C) Biomed Central 